P11.28 'GAY FRIENDLY GP' ONLINE TRAINING: STRENGTHENING CAPACITY OF PRIMARY CARE IN WORKING WITH GAY MEN AND MEN WHO HAVE SEX WITH MEN PATIENTS

${ }^{1} \mathrm{~A}$ Mudie*, ${ }^{2} \mathrm{D}$ Baker* ${ }^{*}{ }^{3} \mathrm{C}$ Pell, ${ }^{4} \mathrm{~J}$ Dabbhadatta*${ }^{5}{ }^{5} \mathrm{~B}$ Crozier, ${ }^{6} \mathrm{~T}$ Munro, ${ }^{6} \mathrm{~J}$ Gray, ${ }^{7} \mathrm{~A}$ Ubrihien, ${ }^{1 \mathrm{~J}} \mathrm{Chu},{ }^{6} \mathrm{~B}$ Clifton, on behalf of the STIs in Gay Men Action Group's Clinicians Communication Project Working Group. 'Australasian Society for HIV Medicine, Australia; ${ }^{2}$ East Sydney Doctors, Australia; ${ }^{3}$ Taylor Square Private Clinic, Australia; ${ }^{4}$ HIVIAIDS and Related Programs Unit, South Eastern Sydney Local Health District, Australia; ${ }^{5}$ Albion Centre, South Eastern Sydney Local Health District, Australia; ${ }^{6}$ ACON, Australia; ${ }^{7}$ Western Sydney Sexual Health Centre, Western Sydney Local Health District, Australia

\subsection{6/sextrans-2015-052270.476}

Introduction Sexually transmissible infections (STIs) including HIV remain a significant public health issue for gay men and men who have sex with men (MSM). General Practitioners (GPs) play an essential role in STI testing and management with over $50 \%$ of testing in NSW occurring within general practice settings. In 2014 the Sydney Gay Friendly GP list was updated by the STIs in Gay Men Action Group and through this process, it was identified that some GPs needed further training.

Methods A literature review was conducted mid-2014 which identified online learning as an effective modality for providing GPs with MSM relevant training. An expert committee was established including GP and community representatives to provide input and guide the development of the online learning module (OLM). Key issues around primary care experiences of MSM were identified and a 60 min self-paced OLM was developed. The interactive OLM aims to increase the competence and confidence of GPs and other health professionals in identifying and addressing issues related to sexual health and wellbeing relevant to MSM.

Results The OLM consists of three modules; towards a better understanding of gay men and MSM, discussing sexual history and testing for STIs, and issues facing this population group. As an incentive for GPs to participate, the Royal Australian College of General Practitioners' Continuing Professional Development points are allocated to those who complete the training.

Conclusion The Gay Friendly GP OLM is Australia's first online training that promotes optimal care for MSM in general practice settings. Responding to the needs of key populations in general practice can help bridge the gap between health professionals and the populations they serve. This training package will assist GPs to improve consumer engagement, understand sexual diversity and promote effective screening and treatment of STIs in gay men and MSM.

Disclosure of interest statement Nil.

\section{P11.29 USING QUALITATIVE RESEARCH METHODS TO ELUCIDATE "EMIC" CONSTRUCTIONS OF RISK AND SEROADAPTIVE BEHAVIOURS AMONG MEN WHO HAVE SEX WITH MEN (MSM)}

${ }^{1}$ RR Patel, ${ }^{2} \mathrm{LN}$ Jacobi, ${ }^{1,2} \mathrm{BP}$ Stoner*. 'Washington University School of Medicine; ${ }^{2}$ Washington University Department of Anthropology, St. Louis, MO, USA

\subsection{6/sextrans-2015-052270.477}

Introduction Anthropologists use qualitative methods to elicit cultural frameworks which structure patterns of behaviour and social organisation. These resultant "emic" models offer a window on the world of meaning for social actors in their engagement with others. We employed ethnographic approaches to investigate how men who have sex with men (MSM) identify potential sex partners, determine partner risk profiles, and adopt specific seroadaptive behaviours and strategies to minimise risk of STI/HIV transmission.

Methods Sexually-active MSM in St. Louis, MO USA were recruited from online advertisements on a variety of social networking sites, as well as flyers posted at bars, clubs, and other venues. Participants completed extended, in-depth qualitative interviews about sex partner selection, sexual practices, and seroadaptive approaches for STI/HIV prevention, including knowledge and use of pre-exposure prophylaxis (PrEP).

Results As of 13 March 2015, 11 subjects were enrolled in the study, with median age 30 (IQR 27 - 35). Participants reported increasingly nuanced categories of partner risk perception, including "HIV-negative plus PrEP," "HIV-negative," "HIV-positive, undetectable," "HIV-positive, detectable," "HIV-positive, unknown viral load" and "HIV-unknown." Serosorting was observed. Seropositioning was universal for HIV prevention subjects reporting active engagement to minimise risk of HIV transmission (but not syphilis or other STIs) to negative or status-unknown partners. Knowledge of PrEP was variable. Emic conceptions of risk invoked existential models of concern for self and others. Adoption and performance of specific behaviours validated and confirmed perceptions of benevolence toward self and others.

Conclusion HIV prevention was highly valued and actively sought by sexually-active MSM. Risk conceptions were mediated through complex understandings of partner risk profiles, and performance of seroadaptive behaviours served to validate perceptions of well-being and benevolence. The need for syphilis prevention was under-appreciated. These findings have implications for improving STI/HIV prevention approaches among MSM.

Disclosure of interest statement Supported with funding from the US Centres for Disease Control and Prevention (CDC).

\section{P11.30 OUT LATER IN LIFE: WORKING WITH OLDER SAME-SEX ATTRACTED MEN}

B Sudarto*. Victorian AIDS Council (VAC)

\subsection{6/sextrans-2015-052270.478}

Introduction Coming to terms with one's sexuality can be a lengthy process. Coming out in this context refers to the process of accepting same-sex attraction and informing others of one's sexual identity. Coming out is different for each individual, with some men come out later in life after years of denying their sexuality.

There are issues specific to this population. These include overcoming internalised prejudice resulting from prolonged exposure to homophobia, disclosing same-sex attraction to their opposite-sex partners and children, as well as re-establishing the self as a gay or bisexual man to their social and professional network.

To date, there are limited services available for men who come out later in life. As a result, many of these men feel isolated, especially from the mainstream youth-centric gay culture. Internalised prejudice can also prevent them from befriending other gay men, seeking support and education. All of these can have a detrimental effect on their well being.

Methods Momentum is a peer-based workshop for same-sex attracted men aged 27 years and above. The workshop provides 